\title{
COMO INSERIR A GESTÃO DO CONHECIMENTO NA ESTRATÉGIA DA EMPRESA?
}

\author{
Maria Celeste Reis Lobo de Vasconcelos \\ Mestrado Profissional em Administração- MPA - Fundação Pedro Leopoldo
}

Geralda da Saúde Ferreira Souza

Mestranda do MPA e colaboradora da PRECON Industrial S. A

\section{RESUMO}

No contexto mundial atual, as empresas precisam implementar continuamente inovações, tecnológicas e gerenciais, para garantirem a capacidade de competir e sobreviver no mercado globalizado. A chamada sociedade do conhecimento tem exigido uma atuação pro ativa por parte da direção das empresas, como forma de inserir a gestão do conhecimento na estratégia das mesmas. Entretanto esta inserção nem sempre é de fácil implementação, os resultados não são obtidos em curto prazo e os funcionários não estão geralmente preparados para as mudanças necessárias.

Este artigo descreve um caso de programa de gestão do conhecimento implementado pela PRECON Industrial, empresa do setor de construção civil, localizada em Minas Gerais. O programa foi proposto pela alta administração da empresa, em parceria com o setor de recursos humanos. É descrita a forma de inserção deste programa na estratégia desta empresa e são analisadas as contribuições do programa para as etapas de geração, aquisição, compartilhamento e registro do conhecimento. São feitas considerações sobre as mudanças introduzidas na gestão dos recursos humanos, visando colocar as pessoas no coração da estratégia empresarial.

Palavras chave: Gestão do conhecimento, Estratégia, Inovação, Competitividade.

\section{INTRODUÇÃO}

Para garantir a capacidade de competir e de sobreviver num mercado exigente, as empresas precisam passar por constantes inovações, tanto em termos de novas tecnologias a serem incorporadas em produtos e processos quanto em relação à implementação de novos modelos de gestão. Como consequiência, a dúvida que se ouve constantemente nos ambientes acadêmico e empresarial é: por que algumas empresas são mais inovadoras do que outras? DAVENPORT \& PRUSAK (1998) afirmam que as empresas mais bem sucedidas são aquelas onde a gestão do conhecimento faz parte do trabalho de todos os seus membros. Já para THUROW (1997), as empresas mais inovadoras são aquelas que estão derrubando as paredes funcionais e criando uma teia entre invenção, projeto, fabricação, vendas, logística e serviços, permitindo que as decisões sejam tomadas nos níveis mais baixos da organização. Com base nestas constatações, várias empresas estão buscando novos modelos de gestão. A chamada sociedade do conhecimento tem exigido uma atuação pro ativa por parte da direção das empresas, como forma de inserir a gestão do conhecimento na estratégia das mesmas. entretanto esta inserção nem sempre é de fácil implementação, os resultados não são obtidos em curto prazo e os funcionários não estão geralmente preparados para as mudanças necessárias.

Este artigo tem o objetivo de descrever um caso exemplo de programa de gestão do 
conhecimento implementado por uma grande empresa do setor de construções préfabricadas de concreto armado localizada no estado de Minas Gerais e fundada em 1963. O programa foi proposto pela alta administração da empresa, em parceria com o setor de recursos humanos. É descrita a forma de inserção deste programa na estratégia desta empresa e são analisadas as contribuições do mesmo para a gestão do conhecimento. São feitas ainda algumas considerações sobre as mudanças que estão sendo introduzidas na gestão dos recursos humanos da empresa, como forma de colocar as pessoas no coração da estratégia empresarial e criar ambientes propícios à inovação.

\section{A PRÁTICA DA GESTÃO DO CONHECIMENTO NAS EMPRESAS}

LEONARD BARTON (1998) mostra que as empresas mais inovadoras são as que demonstram maior competência para gerar e administrar conhecimentos. CHOO (1995) afirma que as empresas que sobrevivem no mercado globalizado têm o conhecimento como principal recurso estratégico. STEWART (1998) introduziu o conceito de "capital intelectual" como sendo a soma do conhecimento de todos em uma empresa, o que lhe proporciona vantagem competitiva. Para ele, gerenciar o capital intelectual deve ser a prioridade número um de uma empresa.

Sabe-se que o conhecimento é, em grande parte, tácito, isto é, algo altamente pessoal, estando enraizado nas experiências do indivíduo, bem como em suas emoções, valores e ideais (NONAKA \& TAKEUCHI, 1997). O fato de o conhecimento ser basicamente tácito exige ambiente propício para sua criação e compartilhamento. Portanto, a tarefa de gerir o conhecimento está longe de ser uma tarefa fácil. Alguns autores já concluíram que a criação de um ambiente de confiança é hoje indispensável à gestão empresarial e que sem ele, o trabalho em equipes, a criatividade e o compartilhamento do conhecimento ficam prejudicados. Este ambiente de confiança, que é gerado através do incentivo à criatividade e ao trabalho voluntário, do fortalecimento da comunicação e da rede de contatos, da solidariedade entre as equipes e da flexibilidade, passa a ter um papel fundamental neste contexto.

CRAWFORD (1994) enfatiza que o capital humano — que significa pessoas estudadas e especializadas - é o ponto central na transformação global. $\mathrm{O}$ autor afirma que:

"Nesta nova economia, informação e conhecimento substituem capital físico e financeiro, tornando-se uma das maiores vantagens competitivas nos negócios; e a inteligência criadora constitui-se na riqueza da nova sociedade.” (1994, pág. 15)

A preocupação com o fortalecimento do capital intelectual tem mudado a gestão dos recursos humanos nas empresas. Observa-se que os processos de recrutamento e seleção têm se modificado, no sentido de usar novas técnicas capazes de identificar pessoas com potencial de crescimento, flexibilidade e pensamento estratégico. As organizações precisam de pessoas capazes de incentivar a criação e comunicação do conhecimento, colocar esse conhecimento numa forma estruturada e mantê-lo ou aprimorá-lo. A necessidade de criação de um ambiente propício à aprendizagem deixou de ter implicações apenas no nível individual, passando cada vez mais pela formação de equipes multidisciplinares. Observa-se que a gerência, principalmente a situada no topo das organizações, deve ser capaz de comunicar a todos os subordinados as estratégias da empresa, de forma que, mesmo aqueles que estão nos níveis hierárquicos inferiores, 
possam tomar decisões alinhadas às mesmas. As iniciativas de gestão do conhecimento demandam, portanto, profissionais que tenham facilidade em gerir relacionamentos entre equipes e com fornecedores externos do conhecimento, tais como clientes, outras empresas e parceiros acadêmicos.

FLEURY \& FLEURY (2000) introduzem o conceito de competência como base de um modelo de gestão de pessoas. Alguns aspectos ressaltados são:

$>$ As políticas adotadas pelas empresas para atrair, desenvolver e reter as pessoas.

$>$ A adoção de políticas de participação dos empregados é vista como sendo uma disposição das empresas para propiciar a melhoria contínua e a aprendizagem.

$>\mathrm{O}$ investimento em treinamento e desenvolvimento dos empregados como forma de desenvolver as competências essenciais para o negócio.

Sobre a participação dos funcionários no processo de elaboração de estratégias, FLEURY \& FLEURY (2000) comentam:

"Para a estratégia conseguir adesão, é necessário que haja participação, isto é, que não seja privilégio de uma minoria pensante, mas seja discutida nas várias esferas da vida organizacional".(p. 63).

STEWART (1998) lembra que na era do capital intelectual as partes mais valiosas dos trabalhos tornaram-se essencialmente tarefas humanas: sentir, julgar, criar e desenvolver relacionamentos. $\mathrm{O}$ trabalhador do conhecimento leva suas ferramentas consigo, em seu cérebro. Na economia baseada no conhecimento, são as atividades inteligentes que agregam valor, ficando menos importantes as atividades rotineiras e manuais.

\section{PRINCIPAIS ETAPAS DA GESTÃO DO CONHECIMENTO}

É possível diferenciar três momentos importantes do processo de gestão do conhecimento: aquisição e criação do conhecimento; compartilhamento e transferência do conhecimento; registro do conhecimento.

A etapa de aquisição e criação inclui o conhecimento adquirido por uma organização e também o conhecimento que ela desenvolve. $\mathrm{O}$ conhecimento adquirido não precisa ser necessariamente recém criado, mas apenas ser novidade para a organização. Observa-se que várias empresas têm procurado enfatizar, através da criação de prêmios, a importância do conhecimento adquirido.

A etapa de compartilhamento e transferência do conhecimento exige um ambiente de confiança, que deve ser estimulado e recompensado. Gerentes do conhecimento bem sucedidos perceberam que o conhecimento é transferido através de múltiplos canais que se reforçam mutuamente. Para isso, os parceiros precisam se reunir regularmente num ambiente que possibilite o contato face a face. GRATTON (2000) também é da opinião que a confiança é fundamental nos processos de transmissão de conhecimentos: os indivíduos precisam confiar uns nos outros e também na organização. Eles precisam sentir que serão recompensados de alguma maneira, o que não envolve necessariamente recursos financeiros. A criação deste ambiente de confiança leva tempo e precisa ser 
estimulada pela empresa. Nesse processo, o papel da comunicação é crucial. Os trabalhos entre grupos distintos representam as melhores ocasiões para transmissão de conhecimentos pois é nas interfaces que surgem novas idéias.

O objetivo da etapa de registro é apresentar o conhecimento numa forma que o torne acessível àqueles que precisem dele. As tecnologias da informação e comunicação permitem uma maior codificação do conhecimento e, portanto, podem acelerar o processo de inovação e mudança. Mas alguns tipos de conhecimento não podem ser efetivamente codificados, pelo menos por escrito.

VASCONCELOS (2000) propõe um modelo para avaliar as três etapas da gestão do conhecimento no ambiente empresarial. As variáveis selecionadas para avaliar a etapa de aquisição e geração do conhecimento versaram sobre o desenvolvimento de competências através de treinamento, o incentivo à participação dos empregados com idéias e sugestões na melhoria de processos e produtos, a abrangência do processo de aprendizagem, a relação da empresa com o ambiente externo e a postura explícita da empresa em relação à criação do conhecimento. Para avaliar a etapa de disseminação, compartilhamento e transferência do conhecimento, as variáveis selecionadas incluíram a sistemática de elaboração da estratégia, o processo de tomada de decisão, a eficiência da comunicação interna, a estrutura organizacional e a postura explícita da empresa em relação ao compartilhamento do conhecimento. Segundo a literatura, estes fatores contribuem para a criação de um bom ambiente de trabalho, onde os funcionários se sentem parte de um único time e capazes de influenciar nas decisões que os afetam, e com isto se sentem seguros para o compartilhamento e a disseminação do conhecimento. Para avaliar a etapa de registro do conhecimento foram selecionadas variáveis relativas ao desenvolvimento de sistemas de informação, à forma de utilização dos resultados dos treinamentos dos empregados e aos esforços para registro explícito do conhecimento.

Observa-se que a gestão do conhecimento tem assumido, assim, uma grande relevância para as empresas de todos os setores da economia. Mas o que é preciso fazer para inserir a gestão do conhecimento na estratégia da empresa? Como é possível envolver todos os funcionários nas práticas de gestão do conhecimento? Os próximos itens descrevem um caso exemplo de programa de gestão do conhecimento implementado por uma grande empresa do setor de construções pré-fabricadas de concreto armado, localizada no estado de Minas Gerais. O programa foi proposto pela alta administração da empresa, em parceria com o setor de recursos humanos. É descrita a forma de inserção deste programa na estratégia desta empresa e são analisadas as contribuições do programa para as etapas de geração, aquisição, compartilhamento e registro do conhecimento.

\section{A EMPRESA PRECON}

A PRECON Industrial S.A. foi fundada em 1963, na cidade de Pedro Leopoldo-MG. É líder no mercado de Minas Gerais no seu segmento. Gera em torno de 565 empregos diretos, é subdividida em unidades de negócios e fabrica quatorze produtos no mesmo parque fabril, diferenciando-se dos seus concorrentes que, em sua maioria, trabalham com um 
único produto.

A PRECON iniciou suas atividades com a produção de pré-fabricados como meio-fio para urbanização de ruas e calçadas, postes para cercas, cochos, mourões para fazendas e muros pré-fabricados.

Entre 1966 e 1967, a PRECON começou a fabricar produtos voltados para a linha industrial, iniciando a fabricação de postes destinados à eletrificação urbana e rural. No início de 1970, começou a fabricar telhas e caixas d'água de fibrocimento.

Até meados de 1980, a PRECON consolidou os investimentos, acumulando e desenvolvendo tecnologia em construções pré-fabricadas de concreto armado e protendido. Nesse período, a Empresa se fortalece e consolida a sua marca e a sua participação no mercado.

Com a abertura de mercado, a competitividade e a concorrência aumentaram significativamente a partir de 1990, provocando profundas transformações na economia brasileira. Iniciam-se, na PRECON, mudanças tanto operacionais quanto gerenciais, buscando o desenvolvimento e crescimento para se adaptar ao momento econômico imposto pelo mercado globalizado. A PRECON busca tecnologias para desenvolvimento e lançamento de novos produtos, com pesquisas no mercado interno e externo, como também em parcerias com centros tecnológicos, universidades e outras instituições, voltadas sempre para o seu negócio, a construção civil.

No ano de 1998, a PRECON lança a linha de telhas residenciais coloridas Granville e a bóia com válvula de esfera. Em 1999, a procura incessante por inovações faz a PRECON buscar parcerias e novamente lançar produtos na linha de ensacados, aço cortado e dobrado para construção civil.

Em 2000, outros produtos entram no mercado com a força da marca PRECON: caixa d'água de polietileno e painel arquitetônico para fachadas.

No final de 2001, nasce uma empresa de prestação de serviços em aço cortado e dobrado para construção civil, a PRECON ESTIRAÇO, consolidando a parceria PRECON, BELGO MINEIRA e ESTIRAÇO.

Em 2002, a Empresa lança a laje alveolar PRECON. Ainda estão sendo desenvolvidas pesquisas para o Projeto Habitacional PRECON, um recurso habitacional com estruturas e painéis mais leves para a construção civil. A expansão da Empresa e a implantação de novos produtos têm exigido um aumento significativo do seu parque industrial, como também o aumento da contratação de pessoal qualificado. A TAB. 1 mostra o nível de escolaridade dos colaboradores. 


\section{TABELA 1}

\section{Colaboradores da PRECON — Número e nível de escolaridade}

\begin{tabular}{ll} 
Empregados & 565 \\
\hline Formação & Quantidade \\
\hline Ensino fundamental & 281 \\
\hline Ensino médio & 181 \\
\hline Ensino Superior & 91 \\
\hline Pós-graduação & 11 \\
Mestrado & 1 \\
\hline
\end{tabular}

FONTE - PRECON INDUSTRIAL S.A.

Levando em consideração que toda mudança impõe reflexões e análises, requerendo ações concretas no sentido de adequar a Empresa às novas exigências profissionais e empresariais, objetiva-se, nesta pesquisa verificar os impactos do mais recente programa lançado pela PRECON, na sua busca constante pela competitividade.

\section{PROGRAMA PRECON VIVA}

O Programa PRECON VIVA foi criado pelo Presidente da PRECON, em março de 2002, dando uma nova caracterização ao Programa SINERGIA PRECON que estava em andamento desde o ano de 2001. Este novo nome se baseou no fato de que uma das estratégias da empresa para os próximos anos é a revitalização da organização empresarial como um todo, principalmente no que tange as políticas de Recursos Humanos.

O Programa PRECON VIVA está ligado à diretoria de Recursos Humanos e desenvolvido de forma integrada com as unidades de negócios. Tem como meta principal envolver, sensibilizar, educar e desenvolver pessoas, através de uma política transparente de recursos humanos ligada à estratégia empresarial, além de proporcionar ambientes de trabalho cada vez mais organizados, limpos, seguros e agradáveis. $\mathrm{O}$ Programa visa recriar o ambiente interno da empresa, envolvendo os colaboradores e o ambiente que os cercam, numa ação conjunta, de forma a criar novos conhecimentos e obter um desempenho global melhor do que aquele demonstrado pela soma do desempenho de cada empregado isoladamente.

\section{OBJETIVOS PRINCIPAIS}

Os objetivos principais do Programa são:

- Manter a PRECON como um organismo vivo.

- Alinhar a Gestão de Recursos Humanos a estratégia de negócios da empresa,

- aproximando cada vez mais o discurso da ação.

- Integrar todas as unidades de negócios e áreas.

- Desenvolver uma cultura empresarial pró-ativa no sentido de fazer com que todos os colaboradores da Empresa desenvolvam esforços coordenados na realização de diversas funções, visando obter um desempenho empresarial melhor do que aquele demonstrado isoladamente.

- Ampliar a visão de cada colaborador em relação às estratégias de cada unidade de negócio, abrindo novas oportunidades de negócios.

- Promover uma maior integração dos colaboradores. 
- Promover o desenvolvimento das pessoas e a preocupação com o autodesenvolvimento.

- Criar ambiente propício a uma mudança cultural no sentido de melhoria da postura profissional em termos de segurança do trabalho, combate ao desperdício, preocupação com a limpeza, maior organização do setor de trabalho, cuidados com os equipamentos de segurança, vestuário, calçado, etc, levando estes conceitos para o ambiente familiar.

- Promover o crescimento e o lucro da empresa

\section{ATIVIDADES PREVISTAS}

Algumas atividades previstas pelo Programa são:

- Revitalizar o meio ambiente com plantio de árvores frutíferas, comedouros para pássaros, reciclagem de rejeitos, etc.

- Envolver as famílias dos funcionários através de visitas a fábrica, concursos, etc.

- Promover estudos do layout das áreas de trabalho, visando aproximar as pessoas.

- Desenvolver lideranças através do treinamento.

- Fortalecer a infraestrutura de tecnologia de informação, através da criação da intranet, criação de sistemas de informação, etc, viabilizando o controle on-line de estoques, acesso ao cadastro dos clientes e fornecedores, etc.

- Desenvolver programas de treinamento visando o atendimento personalizado aos clientes e fornecedores.

O Programa PRECON VIVA foi desenvolvido e estruturado de forma a envolver todos os funcionários da empresa nas várias metas e atividades previstas. As principais ações previstas no programa, assim como os setores envolvidos, foram estruturados num diagrama tipo espinha de peixe, mostrado na Fig. 1, a seguir, que é atualizado constantemente. 


\section{Programa PRECON VIVA}

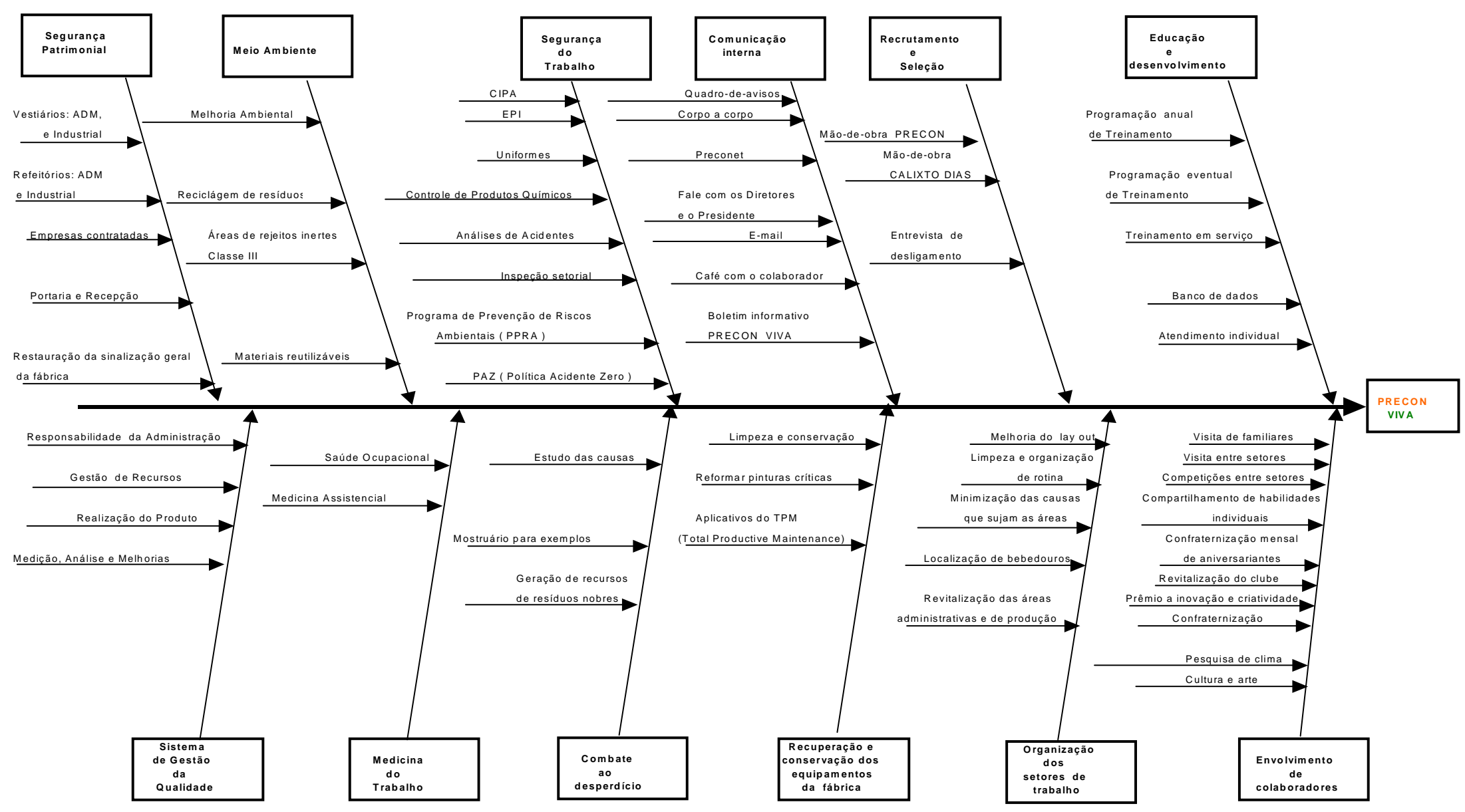

Figura 1 


\section{LANÇAMENTO DO PROGRAMA}

O Programa PRECON VIVA foi lançado oficialmente pela diretoria da empresa no dia 22/5/2002, dentro das festividades de comemoração do Mês do Trabalhador, com a presença de todos os colaboradores.

$\mathrm{Na}$ ocasião, foi apresentada uma peça teatral, bem humorada, com o tema "Zé Modelo", personagem exemplar que reforça o comportamento e os valores que a empresa quer ressaltar. $\mathrm{Na}$ peça foram destacados os compromissos da empresa com a qualidade, segurança, ordem, limpeza, tratamento do meio ambiente, alem da importância da aprendizagem, da solidariedade e do trabalho em equipe. Nesta oportunidade, a equipe coordenadora do Programa juntamente com o "Zé Modelo", apresentou a filosofia do PRECON VIVA durante a peça, convidando todos os presentes a fazerem parte do Programa. O texto da peça teatral foi escrito, dirigido e apresentado por colaboradores PRECON. A área de RH deu todo o suporte necessário: informação, montagens do texto, cenário e assistência durante a apresentação. O sucesso da apresentação teatral foi tamanho que o grupo de teatro ficou consolidado na Empresa a partir desse encontro com o nome Grupo Arte PRECON. Alem do teatro, ainda se apresentou, pela primeira vez nesta ocasião, o Coral e Banda PRECON, formados por colaboradores, que a partir desta data darão suporte a todas as programações culturais da Empresa.

O ambiente que foi criado para o lançamento do programa foi bastante acolhedor e festivo, propício à transmissão da mensagem que o programa encerra. $\mathrm{O}$ clima entre os envolvidos foi sinérgico, de confiança, alegria, satisfação e envolvimento. Durante a encenação percebeu-se que toda a PRECON estava envolvida, emocionada e vivendo aquele momento. Destacam-se as palavras de um dos membros do setor de Recursos Humanos da empresa:

"Para nós, membros do RH, foi como um sonho de anos que se concretizava naquele instante, observando, inclusive, que os colaboradores estão aptos a lidarem com o novo e a criarem".

A reação dos colaboradores foi contagiante e várias mensagens foram transmitidas pessoalmente ou através de e-mail ao setor de RH. Destaca-se:

"O evento foi educativo, a mensagem foi clara; vocês coordenadores do evento estão de parabéns; a peça sendo apresentada pelos próprios colaboradores é muito melhor, pois sentimos pertencentes ao Programa; aprendemos sobre cidadania, combate ao desperdício, limpeza e organização de forma natural"

A empresa teve a preocupação de fotografar e filmar todo o evento com o objetivo de documentar o lançamento do programa, visando divulgação interna e externa em atividades diversas.

\section{O PROGRAMA PRECON VIVA E A GESTÃO DO CONHECIMENTO}

Conforme descrito no item anterior, o programa PRECON VIVA foi proposto pela alta administração da empresa, em parceria com o setor de recursos humanos e faz parte da estratégia empresarial para os próximos anos.

Neste item será feita uma comparação do PRECON VIVA com as práticas da gestão do conhecimento. Serão identificadas as contribuições do Programa para as etapas de geração, aquisição, compartilhamento e registro do conhecimento, conforme modelo de gestão do conhecimento proposto por VASCONCELOS (2000). 
Para esta análise, serão utilizadas as informações disponíveis na estrutura de espinha de peixe apresentada na Fig.1. Várias das atividades listadas contribuem para mais de uma das etapas da gestão do conhecimento, porem serão citadas apenas uma vez.

\section{ETAPA DE AQUISIÇÃO E GERAÇÃO DO CONHECIMENTO}

Para avaliar esta etapa, será analisada a preocupação da empresa com o desenvolvimento de atividades que contribuam para a criação de ambientes propícios à inovação de produtos e

processos. Na Fig. 1 podem ser identificadas:

Programação anual e eventual de treinamento

Treinamento em serviço

Prêmio à inovação e à criatividade

Cultura e arte

Pesquisa de clima

Visita entre setores

\section{ETAPA DE COMPARTILHAMENTO DO CONHECIMENTO}

Nesta etapa serão listadas iniciativas que contribuem para a melhoria da comunicação e para a criação de um bom ambiente de trabalho, onde os funcionários se sintam "parte de um único time", se sintam capazes de influenciar nas decisões que os afetam, e com isto se sintam seguros para o compartilhamento do conhecimento. Na Fig. 1 podem ser identificadas:

Quadro de avisos

"Fale com os diretores e presidente"

E-mail

Café com o colaborador

Boletim informativo

Confraternização

Compartilhamento de habilidades

Melhoria ambiental

Limpeza e conservação

Atendimento individual

Revitalização do clube

Visita de familiares

Organização dos setores de trabalho (todas)

Segurança do trabalho (todos)

Combate ao desperdício (todos)

\section{ETAPA DE REGISTRO DO CONHECIMENTO}

Para avaliar a etapa de registro do conhecimento foram selecionadas atividades que contribuam para a codificação do conhecimento tácito, criando conhecimento explícito que possa fortalecer a estrutura de conhecimento da empresa. Na Fig. 1 podem ser identificadas:

Banco de dados

Preconet

Sistema de gestão da qualidade. 


\section{CONCLUSÕES}

O programa PRECON VIVA foi proposto pela alta administração da empresa, em parceria com o setor de recursos humanos e faz parte da estratégia empresarial da PRECON para os próximos anos.

O artigo mostrou que o programa engloba várias metas e atividades compatíveis com as práticas da gestão do conhecimento nas empresas, envolvendo as etapas de geração e criação do conhecimento, compartilhamento do conhecimento e registro do conhecimento.

$\mathrm{Na}$ descrição do Programa ficam claras as mudanças que estão sendo introduzidas na gestão dos recursos humanos da empresa, como forma de colocar as pessoas no coração da estratégia empresarial e criar ambientes propícios à inovação. Para que isto aconteça, é preciso integrar todas as áreas, fazer com que todos os colaboradores falem a mesma língua e que enxerguem a empresa como um todo. Como conseqüência, pode-se esperar que cada colaborador seja vendedor em potencial dos produtos da empresa, esteja atento às oportunidades internas e externas e que cresça junto da empresa.

É importante observar que a etapa do registro do conhecimento precisa ser fortalecida no âmbito da empresa, através do desenvolvimento de sistemas de informação, com o registro do conhecimento advindo de treinamentos, com procedimentos e normas embutidos em programas de qualidade, com possíveis registros de patentes, etc. Entretanto, outros autores (TERRA, 2000) já constataram, em pesquisas semelhantes, que a etapa de registro do conhecimento representa ainda um grande desafio para a maioria das empresas, na busca da competitividade na sociedade do conhecimento.

Acredita-se que programas desta natureza representem formas adequadas para inserção da gestão do conhecimento na estratégia das empresas, onde a valorização e o envolvimento dos recursos humanos esteja no coração desta estratégia.

\section{REFERÊNCIAS BIBLIOGRÁFICAS}

1- CHOO, C.W. Information management for the intelligent organization. Medford, ND, ASIS, 1995. cap. 3: Managers as information users, p. 51-59.

2- -------. The knowing organization. Oxford: Oxford University Press, 1998.

3- CRAWFORD, Richard . Na era do capital humano: o talento, a inteligência como forças econômicas. Seu impacto nas empresas e nas decisões de investimento. São Paulo: Atlas, 1994.

4- DAVENPORT, Thomas; PRUSAK, Laurence. Conhecimento empresarial: como as organizações gerenciam o seu capital intelectual. Rio de Janeiro: Campus, 1998. 237p.

5- FLEURY, Afonso; FLEURY, Maria Tereza L. Estratégias empresariais e formação de competências; um quebra cabeça caleidoscópico da indústria brasileira. São Paulo: Atlas, 2000. 169p.

6- GRATTON, Lynda. Palavras ao vento. Exame, São Paulo: Abril, p. 36-40, jul. 2000.

7- LEONARD-BARTON, Dorothy. Nascentes do saber - criando e sustentando as fontes de inovação. Rio de Janeiro: Fundação Getúlio Vargas, 1998.

8- NONAKA, I.; TAKEUCHI, H.; Criação de conhecimento na empresa. Rio de Janeiro: Campus, 1997. 358p.

9- STEWART, T. Capital Intelectual; a nova vantagem competitiva das empresas. Rio de Janeiro: Campus, 1998. 
10-TERRA, José Cláudio C. Gestão do conhecimento; o grande desafio empresarial: uma abordagem baseada no aprendizado e na criatividade. São Paulo: Negócio Editora, 2000.

11-THUROW, L. C. O futuro do capitalismo; como as forças econômicas de hoje moldam o mundo de amanhã. Rio de Janeiro: Rocco. 1997.

12-VASCONCELOS, M. C. R. L. Cooperação Universidade Empresa na Pós Graduação: Contribuição para a Aprendizagem, a Gestão do Conhecimento e a Inovação na Indústria Mineira. Belo Horizonte: Escola de Ciência da Informação da UFMG, 2000, 257p. (Tese, Doutorado em Ciência da Informação). 